\title{
Tobacco cessation skills certification in Arizona: application of a state wide, community based model for diffusion of evidence based practice guidelines
}

Myra L Muramoto, Tim Connolly, Louise J Strayer, Jim Ranger-Moore, William Blatt, Robert Leischow, Scott Leischow

University of Arizona College of Medicine, Department of Family and Community Medicine, and University of Arizona College of Public Health, Arizona Program for Nicotine and Tobacco Research, Tucson, Arizona, USA M L Muramoto

University of Arizona College of Public Health, Arizona Program for Nicotine and Tobacco Research T Connolly

L J Strayer

J Ranger-Moore

W Blatt

Arizona Department of Health Services, Tobacco Education and Prevention Program

R Leischow

University of Arizona College of Public Health, Arizona

Program for Nicotine and Tobacco Research, and National Cancer Institute

$S$ Leischow

Correspondence to: Myra L Muramoto, University of Arizona College of Public Health, Arizona Program for Nicotine and Tobacco Research, PO Box 210462 , Tucson, AZ 85721, USA; myram@u.arizona.edu

Received 22 February 2000 and in revised form

28 June 2000 . Accepted 29 June 2000

\begin{abstract}
Objective-To describe the development and preliminary results from a community based certification model for training in tobacco cessation skills in Arizona.

Design-A programme evaluation using both quantitative pre-post measures and qualitative methods.
\end{abstract}

Setting-Arizona's comprehensive tobacco control programme of state funded, community based local projects and their community partners providing tobacco treatment services for geographically, socioeconomically, and ethnically diverse communities.

Intervention-A three tiered model of skills based training emphasising Agency for Health Care Policy and Research guidelines, and utilising a training of trainers approach to build community capacity. Certification roles addressed basic tobacco cessation skills, tobacco cessation specialist, and tobacco treatment services manager.

Participants-Initial target audience was community based local project personnel and their community partners, with later adoption by community organisations unaffiliated with local projects, and the general public.

Main evaluation measures-Process measures: participant satisfaction, knowledge, skills, and self-efficacy. Outcome: participant demographics, community organisations represented, post-training, cessation related activities.

Results-During the model's implementation year, 1075 participants attended certification training, 947 participants received basic skills certificates and 82 received specialist certificates. Pre, post, and three month measures of self efficacy showed significant and durable increases. Analysis of participant characteristics demonstrated broad community representation. At post-training follow up, $80.9 \%$ of basic skills trainees had performed at least one brief intervention and $74.8 \%$ had made a referral to intensive services. Among cessation specialists, $48.8 \%$ were delivering intensive services and $69.5 \%$ were teaching basic skills classes.
Conclusions-Initial experience with Arizona's state wide, community based model for certification of tobacco cessation skills training suggests this model may be a promising method for broad, population based diffusion of evidence based tobacco cessation guidelines.

(Tobacco Control 2000;9:408-414)

Keywords: tobacco cessation; certification; population based; training

Tobacco use has been well established as the most significant preventable cause of death in the USA. ${ }^{1}$ In 1996, the Agency for Health Care Policy and Research (AHCPR) (renamed the Agency for Healthcare Research and Quality) published evidence based guidelines on smoking cessation treatment, concluding that even brief interventions by tobacco cessation interventionists are effective. Despite substantial knowledge about the breadth of provider types who can effectively provide cessation intervention, ${ }^{2-4}$ and which intervention approaches are effective, there still exists a wide gap between this knowledge and its implementation across the full spectrum of potential providers.

Skills training for tobacco cessation interventions in the published literature has generally been targeted toward health care providers and, until recently, focused nearly exclusively on physicians. ${ }^{56}$ Voluntary organisations such as the American Lung Association and the American Heart Association have provided training programmes for intensive cessation services for many years. ${ }^{3}$ Yet, these training strategies have not been widely successful for broadly reaching tobacco users, as the great majority of smokers who quit or attempt to quit do so without any assistance. ${ }^{78}$ As the AHCPR panel noted, "Despite the availability of effective smoking cessation treatments and interventions, many health care professionals are reluctant-or do not know how-to implement them." ${ }^{2}$ This was clearly shown in a recent article, which found that cessation skills continue to be a poorly addressed topic in medical school curricula. ${ }^{9}$ Physician driven intervention strategies, while efficacious in clinical trial settings, have been limited in broader application because of physicians' failure to perform tobacco cessation interventions consistently in actual practice. ${ }^{10-13}$ Indeed, evidence suggests that in health care settings, 
tobacco cessation interventions may be more efficiently and effectively performed by a team approach, employing non-physicians augmenting brief physician advice to quit. ${ }^{14}{ }^{15}$ Potential interventionists often have only a few minutes to intervene, and there are far more interventionists with only a few minutes than those with more time to address tobacco use.

Tobacco use is a broad, population based, public health problem and warrants a population based model for tobacco cessation, with wider application of brief interventions. Although brief interventions have lower efficacy than more intensive interventions, they have a larger public health impact because of their ability to reach larger and more diverse populations. ${ }^{16}$

The purpose of our paper is to describe a broad, public health tobacco cessation model that emphasises skills training and certification in tobacco cessation interventions within existing community based infrastructures, and to present preliminary results from process and initial outcome evaluations of this model. The model encourages the expansion of health care and non-health care tobacco cessation interventionists and uses evidence based cessation strategies. This diffusion approach, ${ }^{17}$ attending to the innovation (tobacco cessation interventions) as well as the channels used to communicate the innovation, ${ }^{18}{ }^{19}$ allows for the development of a community oriented treatment matrix that maximises the total community resource base while best assuring consistent intervention across different treatment programmes.

\section{Development of Arizona's community based model for training and certification in tobacco cessation skills}

In 1994, Arizona passed legislation increasing the excise tax on tobacco and dedicating a portion of the revenue generated to a comprehensive tobacco control programme. Development of Arizona's community based certification model was designed to assist development of cessation interventions within the existing structure of the Arizona Department of Health Services Tobacco Education and Prevention Program (AzTEPP) ${ }^{20}$ and the unique ethnic, sociocultural, and geographic characteristics of Arizona's population. Cessation is a key feature of AzTEPP's comprehensive approach to tobacco control, which provides funding to local tobacco control projects to offer brief and intensive cessation services in their communities. Expanding eligibility for cessation services to include all adults also created the need for a programme to train tobacco cessation service providers.

Through meetings and discussions with state and local community stakeholders regarding the needs and desires for a certification programme, the critical needs of the Arizona context emerged. We determined that in order to promote tobacco cessation at the community level a training and diffusion model should promote behaviour change at the individual, group, organisation and community level, ${ }^{21}$ while also addressing the diversity of
Arizona's population. To accommodate the Arizona context, the training model would ideally have the following characteristics: (1) is community based and inclusive; (2) promotes evidence based cessation interventions of varied intensities; (3) recognises and accommodates various levels of professional training, skill, and interest in tobacco cessation; (4) recognises and accommodates various professional roles with regard to tobacco cessation; (5) builds community capacity that is sustainable; (6) facilitates community ownership and investment; and (7) is adaptable to diverse populations and cultures.

Several considerations led to inclusion of a certification process in the training model. Certification of training would: (1) identify practitioners who have demonstrated sufficient proficiency in a defined set of tobacco cessation skills, thereby facilitating promotion of evidence based treatment practices; (2) facilitate tracking and follow up of training participants to assess role implementation, productivity, link client outcomes to certified practitioners, and implement quality improvement processes; and (3) encourage practitioners to stay current in their treatment knowledge by requiring mandatory continuing education units and re-certification. Additionally, potential training participants might value certification as recognition of their successful completion of training.

We developed a three tiered certification model, which recognises differing contexts, intensities, and professional roles in delivery of tobacco cessation services. In order to build sustainable capacity at the local level we incorporated a training of trainers approach to delivery of the certification model. To maintain relevance and congruence with state and local community needs we instituted an iterative process of training programme development that enhances community capacity, networking, and buy-in as well as curriculum content founded on evidence based best practices in tobacco cessation.

\section{Application of a community based certification model in Arizona}

This community based model for training and certification is delivered through activities of the Arizona Cessation Training and Evaluation (ACTEV) project, a tri-university collaboration between the University of Arizona, Arizona State University, and Northern Arizona University which is funded by AzTEPP. The ACTEV project's major goal is to increase the effectiveness and prevalence of community based tobacco cessation interventions provided by AzTEPP funded local projects by providing: (1) training based on the AHCPR guideline; (2) certification of training; and (3) evaluation of tobacco treatment services. All providers of AzTEPP funded intensive cessation services are required to be certified through ACTEV. Through local recruitment efforts and the state wide media campaign, tobacco users are encouraged to enroll in the state funded intensive cessation 


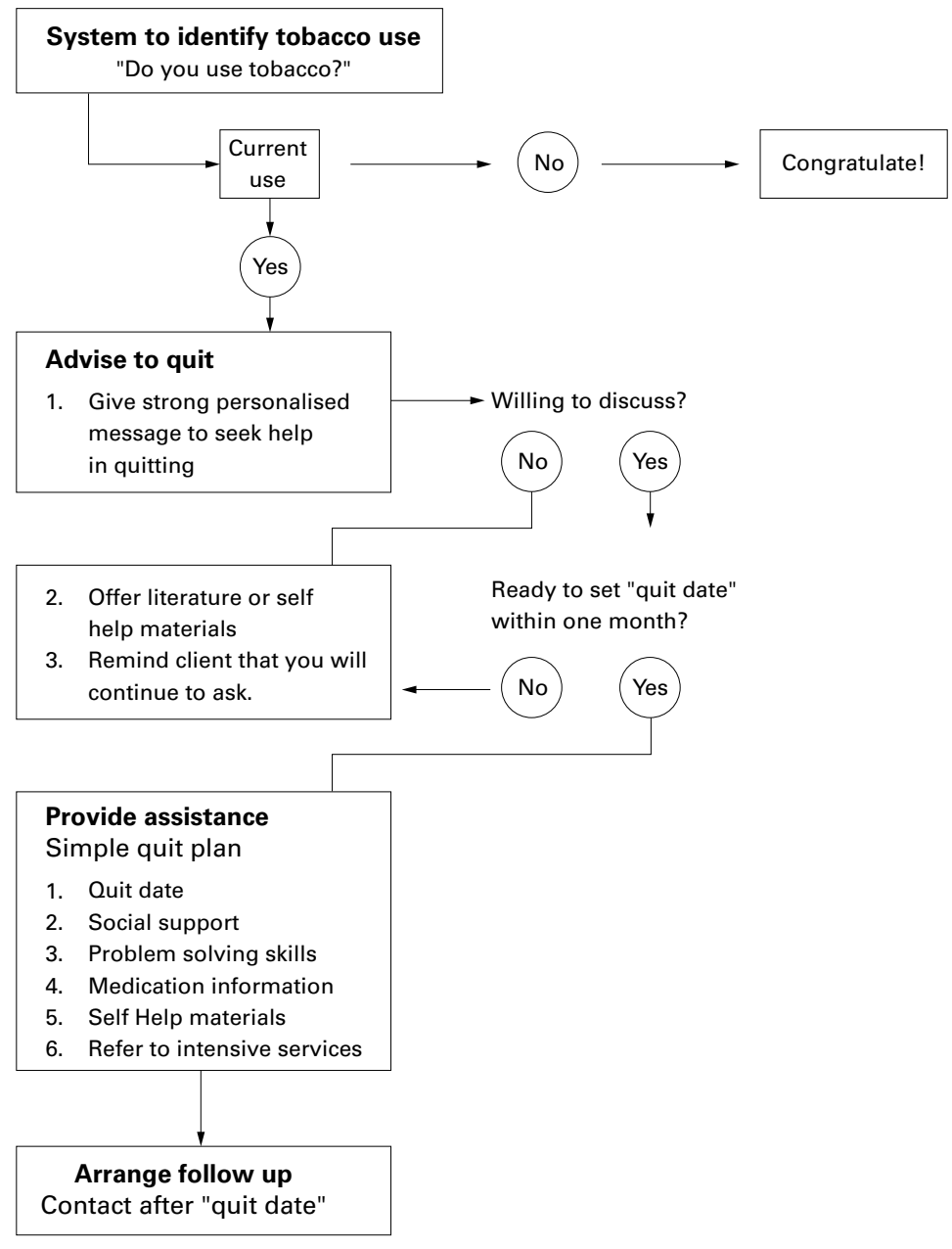

Figure 1 Algorithm to provide guidance for smoking cessation intervention

services offered by the local projects and the state wide, toll free Arizona Smokers' Helpline.

Tobacco cessation roles addressed in Arizona's community based certification model

Three roles are addressed in the certification model or certificate track. The first certificate role is "basic tobacco cessation skills" for persons delivering brief interventions in the context of another service - for example, encounters in a medical or dental office, worksite, school, or faith community. The second certificate role is "tobacco cessation specialist" for professionals delivering intensive tobacco cessation interventions and providing instruction for basic certification. The third certificate role, tentatively titled "tobacco treatment services manager", addresses a role with responsibilities for programme planning, development, and management of tobacco cessation services. This certificate is still under development.

Tobacco cessation training certification is offered for each of the above roles, which correspond to the preparation and function of the person seeking certification and the intensity of the services provided. Curriculum content and training methods for the first two roles are examined below. Features common to training for all three roles are:
(1) certification indicates satisfactory completion of training as evidenced by satisfactory demonstration of skills and a passing score on a written examination;

(2) training is skills based, emphasising practical application of evidence based clinical guidelines and practice standards;

(3) mandatory retraining is required every two years to retain certification.

\section{Basic tobacco cessation skills certificate training}

The "basic tobacco cessation skills" certificate (basic skills) training is population based, inclusive of persons from diverse backgrounds, professions and experience in working with tobacco dependent clients. It assumes and requires no prior knowledge or skills in tobacco cessation. It is intended to educate participants about the health risks of tobacco use, the availability of tobacco treatment services, and to prepare participants to deliver a brief intervention for tobacco cessation within the context of another service or activity. Based upon the AHCPR guideline, the basic skills certificate training prepares participants to assess a client's readiness to quit, to deliver a stage appropriate brief tobacco cessation intervention, and to provide further assistance, referral, and follow up as appropriate. Participants are instructed in the use of an algorithm that provides guidance during the intervention (fig 1).

The basic skills training is a four hour class, delivered by an ACTEV certified tobacco cessation specialist. Training videos and a participant guidebook help to maintain consistency in instruction. Training videos include brief presentations on core content and demonstration role plays depicting a variety of settings including health care, schools and social service programmes. Tools provided to the participants include a pocket sized algorithm outlining the basic steps of a brief intervention, a handout emphasising the benefits of quitting for those not yet ready to quit, a fill-in-the-blank basic quit plan for the tobacco user interested in setting a quit date, and client oriented information cards on pharmacotherapy, to be used as appropriate. To serve Arizona's diverse population, the course is currently available in English, and several adaptations: high acculturation Spanish, low acculturation Spanish, Native American, and pregnant and postpartum women in Women, Infants and Children clinics.

\section{Tobacco cessation specialist certificate training}

The second certificate role is the "tobacco cessation specialist" (cessation specialist). Persons interested in this training must complete an application documenting a minimum level of prior experience in delivering tobacco cessation interventions (at least six months experience in tobacco cessation and at least 15 intensive interventions) and professional training in an area relevant or complementary to the advanced content level. The applicant must also currently hold a basic skills certificate. 
Table 1 Process and outcome evaluation of the Arizona community based certification model

\begin{tabular}{|c|c|c|c|}
\hline Process & Initial outcomes & Intermediate outcomes & Long term outcomes \\
\hline $\begin{array}{l}\text { Satisfaction } \\
\text { - Quality of instruction } \\
\text { - Usefulness of materials } \\
\text { - Relevance of training content } \\
\text { - Quality/value of training overall } \\
\text { Learning } \\
\text { - Knowledge } \\
\text { - Skills } \\
\text { - Self efficacy }\end{array}$ & 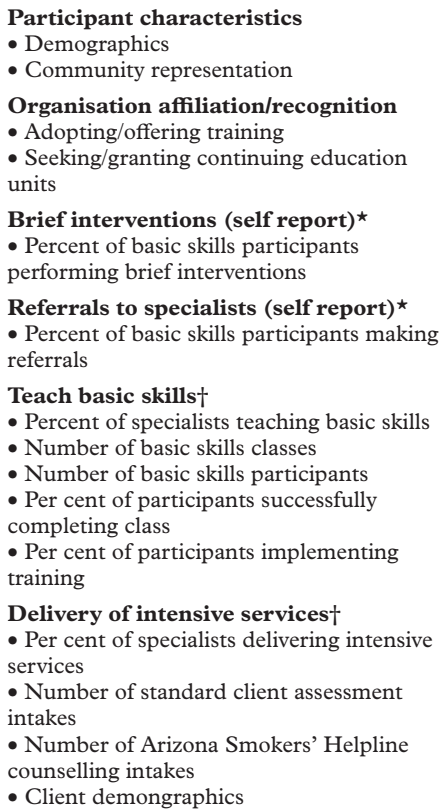 & $\begin{array}{l}\text { Quit attempts } \\
\text { (state surveillance data) } \\
\text { Quit methods } \\
\text { - Standard client assessment intakes } \\
\text { - (State surveillance data) } \\
\text { Clients enter intensive services } \\
\text { - Specialist client referral sources } \\
\text { - Referral sources reported on standard } \\
\text { client intakes } \\
\text { - Arizona Smokers' Helpline client } \\
\text { referral sources } \\
\text { Productivity of basic skills } \\
\text { participants (self report) } \\
\text { - Number of brief interventions } \\
\text { - Sustained brief intervention activity } \\
\text { - Number of referrals } \\
\text { - Sustained referral activity } \\
\text { Client drop out rate† } \\
\text { - Programme drop out survey } \\
\text { Quit rates (intensive services } \\
\text { clients) } \dagger \\
\text { - Standard client assessment follow ups } \\
\text { - Arizona Smokers’ Helpline follow ups }\end{array}$ & $\begin{array}{l}\text { Prevalence of: } \\
\text { - Tobacco use (state surveillance } \\
\text { data) } \\
\text { Quit rates (population)† } \\
\text { - Standard client assessment } \\
\text { follow ups } \\
\text { - Arizona Smokers' Helpline } \\
\text { follow ups } \\
\text { - (State surveillance data) } \\
\text { Quit methods } \\
\text { - Standard client assessment } \\
\text { intakes } \\
\text { - (State surveillance data) } \\
\text { Knowledge of health risks } \\
\text { - (State surveillance data) }\end{array}$ \\
\hline
\end{tabular}

*Applies only to basic skills certificate.

†Applies only to specialist certificate.

The cessation specialist training is a two day, 16 hour workshop. Three core skill sets are addressed in the specialist training:

(1) ability to provide multi-session tobacco cessation services within the structure of an existing programme;

(2) ability to act as a resource for other health and human service professionals and community members regarding tobacco issues;

(3) ability to provide instruction for the basic tobacco cessation skills certificate.

Participants are prepared to apply cessation specialist training within the context and limitations of their professional role and previous tobacco cessation training. Intensive, or multisession, tobacco cessation services are offered within the structure of an established programme that the cessation specialist has been trained to deliver-for example, American Lung Association's Freedom from Smoking programme, or American Cancer Society's Fresh Start programme. Training materials include a curriculum guidebook, a resource kit containing a variety of ready-to-use client educational, assessment and recruitment materials, and materials to help assess an existing programme's adherence with AHCPR guidelines. The training to teach basic skills classes emphasises the creation of referral networks that complement and support more intensive services offered by the specialist. The networks of basic skills trained individuals created by a specialist have an established relationship with the specialist, facilitating referrals to the specialist's more intensive services. The specialist's first basic skills training is observed as part of the skills demonstration to ensure quality of instruction.
The observed training must be satisfactorily completed within three months after taking the specialist course. Continuing education units are required to retain current cessation specialist certification.

\section{Evaluation methods}

Evaluation of the certification model addresses process and outcome, using both quantitative and qualitative methods for data collection. Measures collected for evaluation of both the basic skills class and the cessation specialist course are described in table 1. This paper focuses on process and selected initial outcomes. Data collection for intermediate and long-term outcome is still in progress. Participant satisfaction for process measures were all rated on a five point Likert scale. As self efficacy, knowledge, and skills are all important predictors of behaviour change, ${ }^{22} 23$ we used knowledge post-test, pre-post measures of self efficacy, and an observation checklist assessing brief intervention skills demonstrated in standard instructor role plays. An open book knowledge exam is used because its major purpose is to measure participant's ability to comprehend and access information presented, rather than discriminate based on information committed to memory during the training. Data are gathered at the training location for pre-training and post-training surveys, and by mail and telephone for the three and six month follow up.

\section{Analysis}

For the knowledge test, individuals must demonstrate ability to access information presented by achieving a passing grade of $80 \%$ on the 25 
Table 2 Pretest and post-test self efficacy measures for basic skills and specialist training participants

\begin{tabular}{|c|c|c|}
\hline $\begin{array}{l}\text { Basic skills self efficacy } \\
(1=\text { definitely not confident, } 5=\text { definitely confident })\end{array}$ & $\begin{array}{l}\text { Pretest } \\
\text { (mean) }\end{array}$ & $\begin{array}{l}\text { Post-test } \\
\text { (mean) }\end{array}$ \\
\hline 1. I can accurately assess my clients' motivation to quit & 3.24 & $4.55^{\star}$ \\
\hline $\begin{array}{l}\text { 2. I can explore issues related to smoking and quitting, even with } \\
\text { someone not interested in quitting }\end{array}$ & 3.17 & $4.43^{\star}$ \\
\hline 3. I can accurately assess the dependence level of my clients & 2.89 & $4.29^{\star}$ \\
\hline $\begin{array}{l}\text { 4. I can provide clients with accurate information regarding the health } \\
\text { benefits of quitting }\end{array}$ & 3.55 & $4.63^{\star}$ \\
\hline 5. I can personalise the benefits of quitting with each individual client & 3.27 & $4.57^{\star}$ \\
\hline $\begin{array}{l}\text { 6. I can provide clients with simple advice and instructions about } \\
\text { nicotine replacement therapy }\end{array}$ & 3.37 & $4.65^{\star}$ \\
\hline 7. I can help clients develop a personalised plan for quitting & 3.36 & $4.56^{\star}$ \\
\hline 8. I can arrange for appropriate follow up for my clients & 3.08 & $4.63^{\star}$ \\
\hline $\begin{array}{l}\text { Specialist self efficacy } \\
\qquad(1=\text { definitely not confident }, 5=\text { definitely confident })\end{array}$ & $\begin{array}{l}\text { Pretest } \\
\text { (mean) }\end{array}$ & $\begin{array}{l}\text { Post-test } \\
\text { (mean) }\end{array}$ \\
\hline $\begin{array}{l}\text { 1. I can act as a resource for other health and human service } \\
\text { professionals regarding tobacco cessation }\end{array}$ & 2.98 & $4.08 \dagger$ \\
\hline 2. I can explain Arizona's tobacco cessation certification process & 2.84 & $4.31+$ \\
\hline $\begin{array}{l}\text { 3. I can provide intensive services within the structure of an existing } \\
\text { programme }\end{array}$ & 3.01 & $4.39 \dagger$ \\
\hline 4. I can describe and relate the AHCPR clinical practice guidelines & 3.07 & $4.00 \dagger$ \\
\hline 5. I am able to act as an instructor for basic skills certification & 2.44 & $3.92 \dagger$ \\
\hline 6. I can make arrangements for a basic skills training & 3.07 & $4.27 \dagger$ \\
\hline $\begin{array}{l}\text { 7. I can determine tobacco cessation services' compliance with the } \\
\text { AHCPR clinical practice guidelines }\end{array}$ & 3.53 & $4.46 \dagger$ \\
\hline $\begin{array}{l}\text { 8. I can use the intake and follow up standardised instruments with } \\
\text { clients }\end{array}$ & 2.72 & $3.90 \dagger$ \\
\hline $\begin{array}{l}\text { 9. I can give a brief explanation of the content and goals of the basic } \\
\text { skills training }\end{array}$ & 2.42 & $4.51 \dagger$ \\
\hline 10. I can help a client create a simple quit plan & 2.83 & $4.17 \dagger$ \\
\hline
\end{tabular}

${ }^{\star}$ All pre-post changes in self efficacy scores were significant $(\mathrm{p}<0.01)$.

†All pre-post changes in self efficacy were significant $(p<0.05)$.

item multiple choice exam. Descriptive statistics of satisfaction measures are used for quality assurance and programme improvement. Self efficacy is assessed via a two way analysis of variance (ANOVA) and Bonferroni corrected $t$ tests. Trainee's mean response rate to all questions serves as the outcome variable, and training site location and time point (pre-, post-, three month, six month) serve as independent variables. Non-parametric versions of these tests are used at the level of the individual question.

\section{Results}

During the first year of programme implementation, 1075 participants attended certification training, 947 received basic skills certificates and 82 received specialist certificates. Forty six participants took the specialist certificate course, but had not received certificates for the following reasons: had not yet completed the required skills demonstration; failed to complete the skills demonstration within the three month post-course time limit; or audited the course as part of an administrative role.

RESULTS FOR CERTIFICATION MODEL PROCESS MEASURES

Basic skills certificate

Overall, 947 enrollees completed basic skills training and 82 completed specialist training. Satisfaction with basic skills training was generally high. Usefulness of training materials had an average (SD) rating of $4.74(0.48)$ ). ( $1=$ "not useful" and $5=$ "very useful") (table). The average rating for percentage of class content that was professionally relevant was $4.42(0.75) \quad(1=$ " $0 \%$ relevant" and $5=$ " $100 \%$ relevant"). The average rating for overall quality of the training was $4.35(0.74)$
( $1=$ "poor" and $5=$ "excellent") and overall value of the training was $4.53(0.73)(1=$ "not valuable" and $5=$ "very valuable").

Learning (knowledge, skills and self efficacy)-The average (SD) score on the 25 item post-training basic skills knowledge test was $90.1(7.8) \%$, not unexpected for an "open book" test. The great majority of participants $(99.4 \%)$ passed the 53 item basic skills observation skills checklist on the first attempt reflecting mastery of skills during training. Changes in self efficacy measures (table 2) were not affected by location, implying that training has been conducted uniformly across sites. Self efficacy at post-training and three month follow up differed significantly from pre-training ( $p<0.001$ in each case), but did not differ significantly from each other $(p=0.57)$. This suggests that training not only raised confidence levels significantly, but that the gains have carried over into the field. This finding is encouraging because increased confidence immediately post-training may be more influenced by satisfaction with the training, whereas sustained increases in confidence may be taken as a stronger indicator of training effectiveness.

Individual questions all showed significant increases from pre-training to post-training. Between post-training and three month follow up, two questions showed a significant decline. These questions assessed confidence in exploring quitting related issues with individuals not interested in quitting, and in helping clients to explore past experiences in order to apply them to future quit attempts. These declines may arise from a shortcoming in the training itself, or they may simply stem from real world practice being more challenging than believed by trainees at the conclusion of training. In either case, the ability to detect such changes over time will help focus ongoing curriculum improvement.

\section{Cessation specialist certificate}

Satisfaction with specialist training was generally high. Usefulness of training materials had an average (SD) rating of $4.70(0.56)(1=$ "not useful" and $5=$ "very useful"). The average rating for training meeting professional needs was 4.16 (0.71) ( 1 = "very poor" and $5=$ "excellent") and overall value of the training was $4.45(0.71)$ ( 1 = "not valuable" and 5 = "very valuable").

Learning (knowledge, skills, and self efficacy) - The average (SD) score on the 25 item post-training knowledge test was 92.2 (5.8) $\%$, the average score on the 48 item skills demonstration checklist was 44.3 (3.3)\%, with the great majority of participants $(96.4 \%)$ passing on the first attempt. As with the basic skills classes, self efficacy scores did not differ by site, and increased significantly for every question (table 2).

RESULTS FROM CERTIFICATION MODEL INITIAL OUTCOMES

Participant characteristics

Basic skills certificate-As illustrated in table 3, the majority of participants were female. The 
Table 3 Demographic characteristics of certification participants

\begin{tabular}{|c|c|c|c|c|c|}
\hline & \multicolumn{2}{|c|}{ Basic skills } & \multicolumn{2}{|c|}{$\begin{array}{l}\text { Cessation } \\
\text { specialists }\end{array}$} & \multirow{2}{*}{$\begin{array}{l}\text { Arizona's } \\
\text { population } \\
(\%)\end{array}$} \\
\hline & $n$ & $\%$ & $n$ & $\%$ & \\
\hline \multicolumn{6}{|l|}{ Sex } \\
\hline Female & 718 & 75.8 & 71 & 86.6 & 50.1 \\
\hline Male & 229 & 24.2 & 11 & 13.4 & 49.9 \\
\hline \multicolumn{6}{|l|}{ Age(years) } \\
\hline $15-24$ & 169 & 18.7 & 4 & 5.1 & 13.7 \\
\hline $25-34$ & 234 & 25.9 & 30 & 38.5 & 15.2 \\
\hline $35-44$ & 202 & 22.4 & 19 & 24.4 & 15.3 \\
\hline $45-54$ & 220 & 24.4 & 20 & 25.6 & 11.5 \\
\hline $55-64$ & 65 & 7.2 & 5 & 6.4 & 7.9 \\
\hline $65+$ & 12 & 1.3 & 0 & - & 13.9 \\
\hline \multicolumn{6}{|l|}{ Ethnicity } \\
\hline White & 581 & 62.2 & 50 & 64.9 & 68.0 \\
\hline Hispanic American & 210 & 22.5 & 20 & 26.0 & 20.9 \\
\hline African American & 40 & 4.3 & 2 & 3.1 & 3.5 \\
\hline Native American & 40 & 4.3 & 1 & 1.3 & 5.6 \\
\hline Asian/Pacific Islander & 16 & 1.7 & 0 & - & 2.0 \\
\hline Multicultural & 45 & 4.8 & 4 & 5.2 & - \\
\hline Other (self described) & 2 & 0.2 & 0 & - & - \\
\hline \multicolumn{6}{|l|}{ Geographic location } \\
\hline Urban & 623 & 66.1 & 53 & 64.6 & 82.6 \\
\hline Rural & 320 & 33.9 & 29 & 35.4 & 17.4 \\
\hline Total for each category & 947 & 100.0 & 82 & 100.0 & 100.0 \\
\hline
\end{tabular}

ages of participants ranged from 15 to 75 years, with the vast majority less than 55 years. All of Arizona's ethnic groups are represented, with proportions closely corresponding to the distribution of ethnic groups in the state. Participants' occupational fields demonstrated broad representation of communities with the majority of participants representing public health $(45.6 \%)$ or health care institutions $(28.1 \%)$. Also represented were: schools $(13.6 \%)$, community organisations $(5.3 \%)$, and businesses (1.4\%).

Cessation specialists-As cessation specialists are a subset of basic skills participants, the demographic distribution (table 3 ) is quite similar. Since specialists are engaged in delivery of intensive cessation services, often through contracts with local projects, specialists' organisational representation concentrated in the public health $(54.9 \%)$ and health care $(29.3 \%)$ categories. Also represented were schools $(2.4 \%)$ and community organisations $(7.3 \%)$. Specialists are well represented in rural areas, an important finding as expanding cessation services to rural and underserved communities is a programme goal.

Table 4 Post-training cessation related activities for basic skills and specialist participants

\begin{tabular}{lll}
\hline & $n$ & $\%$ \\
\hline Basic skills post-training cessation related activities (n=497) & & \\
Have performed at least 1 brief intervention since completing training & 402 & 80.9 \\
Have performed a brief intervention in the past 30 days & 291 & 58.6 \\
$\begin{array}{l}\text { Have made at least 1 referral to intensive services since completing } \\
\text { training }\end{array}$ & $330^{\star}$ & $74.8^{\star}$ \\
Have made a referral to intensive services in the past 30 days & $259^{\star}$ & $57.5^{\star}$ \\
Specialist post-training cessation related activities (n=82) & 40 & 48.8 \\
$\begin{array}{l}\text { Delivering intensive services } \\
\text { Teaching tobacco cessation basic skills classes }\end{array}$ & 57 & 69.5 \\
$\quad \begin{array}{l}\text { Delivering intensive services and teaching tobacco cessation basic skills } \\
\text { classes }\end{array}$ & 29 & 35.4 \\
\hline
\end{tabular}

$\star 416$ respondents. Since missing data were non-random, the percentage of basic skills participants making referrals was conservatively adjusted downward based on analyses of respondents. The percentage of "referrals since completing training" was adjusted down from $79.3 \%$, and "referral in the past 30 days" was adjusted down from $62.3 \%$.
POST-TRAINING CESSATION ACTIVITIES

Basic skills certificate - Table 4 shows results of telephone follow up of basic skills participants who were at least six months post-training. The great majority of participants reported they had implemented their training by conducting a brief intervention and making a referral to more intensive services.

Cessation specialists - Post-training cessation related activities of specialists are tracked by their requests for basic skills class materials and by data gathered from standard client assessment questionnaires administered to all clients enrolling in the specialists' intensive services. Approximately half $(48.8 \%)$ of specialists were engaged in delivering intensive cessation services (table 4). A larger percentage of specialists were engaged in teaching basic skills classes, possibly reflecting some local projects' emphasis on educational activities, and that specialist trainings had preceded some local projects' full implementation of cessation services.

\section{Discussion}

Overall, participants in the certification model demonstrated satisfaction with the training, evidence of both knowledge and skills in tobacco cessation interventions as well as significant gains in self efficacy relevant to tobacco cessation interventions. More importantly, both basic skills and specialist participants have implemented their training. Demand for certification training, particularly the basic skills class, remains steady, with the majority of training requests coming from community sources outside of local projects and their direct community partners. There are currently about five basic skills classes per week throughout Arizona. Demographics of certification participants parallel those of the general Arizona population, with over representation of rural areas, implying that at least a basic level of tobacco cessation skills will be available to communities throughout the state, thereby increasing the potential for broad population exposure.

The professions and types of community organisations represented by certification participants include newcomers to tobacco cessation services as well as those already engaged in delivering cessation services. These data, together with the types of community and professional organisations recognising the basic skills and specialist certificates as continuing education units demonstrate that a certification model can be highly inclusive of a broad range of professions, professional roles, and community organisations. The continued offering of basic skills certification classes by specialists suggests that participants and their communities have adopted the certification process and are able to perpetuate the basic skills training within their home communities. Additional research is needed to understand better the impact of the certification model on creating brief intervention referral networks that feed into more intensive tobacco specialist services, and how these services relate to client outcomes. 
Tobacco cessation intervention is an important part of a comprehensive tobacco control strategy. ${ }^{24}$ Although the AHCPR guideline for cessation has been widely available since 1996, widespread implementation of these recommendations has lagged far behind. With the upcoming release of the updated tobacco cessation guidelines by the Agency for Healthcare Research and Quality, public health and health services professionals will face renewed challenges to improve the quality and broaden the reach of evidence based tobacco treatment services at the community level.

Widespread diffusion of evidence based tobacco treatment practices is a daunting public health task, and one that is far from complete. Dissemination of national treatment recommendations can readily occur at a macro level, yet dissemination at a local community level still faces many challenges. Community perception of and buy-in to the value of evidence based treatment is a critical step in the adoption of these recommendations. Promoting skill acquisition, increasing self efficacy, and facilitating practice of tobacco treatment skills will help foster implementation of evidence based practice by service providers at the local level. Maintenance of evidence based treatment practices requires an increase in community capacity that is sustainable..$^{25}$ In short, the challenge is to translate evidence based treatment recommendations into relevant, effective, sustainable practices at the local level. The challenges can be even greater with more diverse communities such as those in other states or other countries. Initial results presented here are promising that a community based model of certification may be an effective method to meet these challenges through enhancing dissemination, soliciting adoption, facilitating implementation, and building sustainable community capacity in evidence based tobacco treatment practices.

Support for this work was in part by funding through the Arizona Department of Health Services Tobacco Education and Prevention Program. Support for manuscript preparation was through the University of Arizona. The authors would like was through the University of Arizona. The authors would like
to acknowledge Hal Strich and Louise Warrick for their editorial contributions to the manuscript.

1 Lynch B, Bonnie R. Growing up tobacco free. Washington DC: National Academy Press, Institute of Medicine, 1994 Fiore MC, Bailey WC, Cohen SJ, et al. Smoking cessation: Clinical Practice Guideline No 18. Rockville, Maryland: US Department of Health and Human Services, Public
Health Service, Agency for Health Care Policy and Health Service, Agency for Health Care Policy and
Research, April 1996. (AHCPR Publication No 960692.); < http://text.nlm.nih.gov>.

3 Lando H. (1987) Lay facilitators as effective smoking cessation counselors. Addict Behav 1987;12:69-72.

4 Stillman FA, Bone LR, Rand C, et al. Heart, body and soul: a church-based smoking cessation program for urban African-Americans. Prev Med 1993;22:335-49.

5 Manley M, Epps RP, Husten C, et al. Clinical interventions in tobacco control: a National Cancer Institute training in tobacco control: a National Cancer Institute
program for physicians. $¥ A M A 1991 ; 11: 3172-3$.

6 Okene JK, Zapka J. Changing provider behaviour: provider education and training. Tobacco Control 1997;6:563-7.

7 Fiore MC, Novotny TE, Pierce JP, et al. Methods used to quit smoking the the United States. Do cessation programs help? fAMA 1990;263:2760-5.

8 Zhu SH, Melcer T, Sun J, et al. Smoking cessation with and without assistance: a population-based analysis. Am f Prev Med 2000;18:305-11.

9 Ferry LH, Grissino LM, Runfola PS. Tobacco dependence curricula in US undergraduate medical education, $7 A M A$ 1999;282:825-9.

10 Frank E, Winkleby MA, Altman DG, et al. Predictors of physicians' smoking cessation advice. 'FAMA 1991; 266:3139-44

11 Gilpin EA, Pierce JP, Johnson M, et al. Physician advice to quit smoking: results from the 1990 California tobacco survey. F Gen Intern Med 1993;8:549-53.

12 Jaén CR, Stange KC, Tumiel LM, et al. Missed opportunities for prevention: smoking cessation counseling and the competing 348 -54.

13 Humair JP, Ward J. Smoking-cessation strategies observed in videotaped general practice consultations. Am F Prev Med 1998;14:1-8.

14 Hollis JF, Lichtenstein E, Vogt TM, et al. A. Nurse-assisted counseling for smokers in primary care. Ann Intern Med 1993;118:521-5.

15 Lichtenstein E, Hollis JF, Severson HH, et al. Tobacco cessation interventions in health care settings: rationale, model, outcomes. Addict Behav 1996;21:709-20.

16 Abrams DB, Orleans CT, Niaura RS, et al. Integrating individual and public health perspectives for treatment of tobacco dependence under managed health care: a combined stepped-care and treatment matching. Ann Behav Med 1996;18:290-304.

17 Rogers EM. Diffusion of innovations, 3rd ed. New York: Free Press, 1983.

18 Green LW, Gottlieb NH, Parcel GS. Diffusion theory extended and applied. In: Ward WB, ed. Advances in health education and promotion. Greenwich, Connecticut: JAI Press, 1987.

19 Oldenburg B, Hardcastle DM, Kok G. Diffusion of innovations. In: Glantz K, Lewis FM, Rimer BK, eds. Health behavior and health education, 2nd ed. San Francisco: Jossey-Bass Publishers, 1997.

20 Arizona Department of Health Services Tobacco Education and Prevention Program (AzTEPP). http://www.tepp.org

21 Elder JP, Geller ES, Hovell MF, et al. Motivating health behavior. Albany, New York: Delmar, 1994.

22 Bandura A. Self efficacy: toward a unifying theory of behavioral change. Psychol Rev 1977;84:191-215.

23 Bandura A. Social foundations of thought and action: a social cognitive theory. Englewood Cliffs, New Jersey: Prentice Hall, 1986.

24 Centers for Disease Control. Best practices for comprehensive tobacco control programs-August 1999. Atlanta, Georgia: US Department of Health, Centers for Disease Control and Prevention, National Center for Chronic Disease Prevention and Health Promotion, Office on Smoking and Health. August 1999. Reprinted, with corrections.

25 National Cancer Policy Board, Institute of Medicine, National Research Council. State programs can reduce tobacco use. Washington DC: National Academy of Sciences, 2000 